Check for updates

Cite this: RSC Adv., 2019, 9, 30489

\title{
Effects of reduced severity of ammonium sulfite pretreatment on bamboo for high cellulose recovery
}

\begin{abstract}
Liyue Zhang, Yue Liu and Zhiqiang Li (1D*
In this study, the conditions for the pretreatment of bamboo by ammonium sulfite to achieve high cellulose recovery were investigated and optimized. To obtain higher cellulose recovery under low-severity pretreatment conditions such as ammonia sulfite concentration, pretreatment time and pretreatment temperature, three-factor and three-level experiments were designed by the Box-Behnken design based on response surface methodology. The results showed that the cellulose recovery yield after $48 \mathrm{~h}$ enzymatic hydrolysis could reach 58.36-59.87\%; moreover, the recovered cellulose was pretreated with $20 \%$ ammonium sulfite at $150{ }^{\circ} \mathrm{C}$ for $6 \mathrm{~h}$, and the obtained yield was in agreement with the predicted yield $(58.87 \%)$. It was about 13 -fold higher than that of the untreated bamboo $(4.41 \%)$. Pretreatment temperature and ammonia sulfite concentration are significantly important factors than pretreatment time in the design space for achieving high cellulose recovery. Moreover, SEM analysis of the pretreated bamboo substrate under optimized conditions illustrated that the biomass surface had become more rough and porous after pretreatment.
\end{abstract}

Received 19th August 2019

Accepted 12th September 2019

DOI: $10.1039 / \mathrm{c} 9 \mathrm{ra06475c}$

rsc.li/rsc-advances
Numerous pretreatment technologies, such as acid-based pretreatments, ${ }^{7} \quad$ alkali-based pretreatments, $^{8}$ organosolv pretreatments, ${ }^{9}$ ionic liquid pretreatments, ${ }^{10}$ and physically assisted chemical pretreatments, ${ }^{11}$ have been studied to remove lignin, break the resistance and depolymerize cellulose for fermentable sugar production.

Sulfite pretreatment is a traditional way in the pulping industry for papermaking; it can be conducted in a wide range of $\mathrm{pH}$ and temperature, which has been described in a textbook. ${ }^{12}$ The goal of pulping is to remove lignin as much as possible without the concurrent loss and degradation of hemicellulose and cellulose; this would lead to a pulp with high yield and strength. ${ }^{13}$ Sulfite process has also been used for pretreating wood chips, ${ }^{12}$ and it has been first used for softwoods (spruce and red pine) through enzymatic saccharification. The result of the study showed that the sulfite-treated softwood chips could significantly become soft, and the enzymatic cellulose conversion yield of over $90 \%$ was achieved. ${ }^{13}$ Then, alkaline sulfite or acid sulfite has been used for the pretreatment of other lignocellulosic biomass such as bamboo ${ }^{\mathbf{1 4}}$ and switchgrass. ${ }^{15}$ In the pretreatment process, the active reagents could be sulfite $\left(\mathrm{SO}_{3}{ }^{2-}\right)$, bisulfite $\left(\mathrm{HSO}_{3}{ }^{-}\right)$, or a combination of two of the three reagents sulfite $\left(\mathrm{SO}_{3}{ }^{2-}\right)$, bisulfite $\left(\mathrm{HSO}_{3}{ }^{-}\right)$, and sulfur dioxide $\left(\mathrm{SO}_{2}\right.$, or $\mathrm{H}_{2} \mathrm{SO}_{3}$ ) depending on the $\mathrm{pH}$ value of the pretreatment liquor at pretreatment temperature. $^{\mathbf{1 6}}$

Ammonium sulfite as a kind of neutral sulfite has been used for papermaking for a long time ${ }^{\mathbf{1 7}}$ and can be easily decomposed into ammonia and sulfite at about $70^{\circ} \mathrm{C}$. Therefore, the effects of the pretreatment of ammonium sulfite and sodium sulfite can be
Key Laboratory of National Forestry and Grassland Administration, Beijing Co-built on Bamboo and Rattan Science and Technology, International Centre for Bamboo and Rattan, Beijing 100102, China.E-mail: lizq@icbr.ac.cn 
Table 1 Experimental factors and levels of ammonium sulfite pretreatment in the Box-Behnken design

\begin{tabular}{lllc}
\hline & \multicolumn{2}{l}{ Factors } \\
\cline { 2 - 4 } $\begin{array}{l}\text { Coded levels } \\
\text { of factors }\end{array}$ & $\begin{array}{l}\text { Ammonium sulfite } \\
\text { concentration (wt } \%)\end{array}$ & Time (h) Temperature $\left({ }^{\circ} \mathrm{C}\right)$ \\
\hline Low level $(-1)$ & 10 & 3 & 120 \\
Central level $(0)$ & 20 & 6 & 150 \\
High level $(1)$ & 30 & 9 & 180
\end{tabular}

significantly different. Ammonium sulfite may exhibit the effects of both ammonia and sulfite on the pretreated bamboo. However, only few studies have been reported on the pretreatment of lignocellulosic biomass. It was first used for wheat straw, and the result demonstrated that ammonium sulfite could significantly improve the enzymatic hydrolysis but under a more severe pretreatment condition; since bamboo is more rigid and compact than wheat straw, harsh pretreatment conditions would be needed. ${ }^{18}$ Hence, considering the pretreatment cost and the final value of the produced glucose, the ammonia sulfite pretreatment conditions of bamboo need to be optimized. The aim of this study was to find low-severity pretreatment parameters (pretreatment temperature, time, and ammonia sulfite concentration) to achieve higher cellulose recovery yield. Milled bamboo was selected as feedstock, and a series of pretreatments were performed based on the Box-Behnken design involving three variables: pretreatment temperature, time, and ammonia sulfite concentration. The total cellulose recovery yield (TCRY) was calculated by enzymatic hydrolysis efficiency obtained after $48 \mathrm{~h}$ enzymatic hydrolysis multiplied with the solid recovery rate after the ammonia sulfite pretreatment. Environmental scanning electron microscopy was conducted to compare the structural changes of raw bamboo and the preferred pretreated substrate.

\section{Materials and methods}

\subsection{Raw materials and reagents}

The raw moso bamboo was four-year-old, obtained from the Guangxi Zhuang Autonomous Region, China. The air-dried bamboo was ground and passed through a 40-60 mesh sieve (the length $\leq 2 \mathrm{~mm}$ ); then, the milled bamboo powder was stored in a sealed plastic bag at room temperature until pretreatment. The moisture contents of the ground bamboo powder and pretreated substrates were determined by drying them in an oven at $103 \pm 2{ }^{\circ} \mathrm{C}$ for $24 \mathrm{~h}$. Chemically pure ammonium sulfite was obtained from Rhawn Reagent Company (Shanghai, China). All the other chemicals in this study were purchased from Sinopharm Chemical Reagent (Beijing) Co., Ltd. (China) and were of analytical grade. Commercial enzymes, i.e. Celluclast $1.5 \mathrm{~L}$ (cellulase) and Novozyme 188 ( $\beta$-glucosidase), were received from Novozymes. All the analysis and experiments were conducted in duplicate.

\subsection{Pretreatment}

Pretreatments were conducted in a $100 \mathrm{~mL}$ hydrothermal reactor with a Teflon-lined steel autoclave; herein, $5 \mathrm{~g}$ raw bamboo material and $30 \mathrm{~mL}$ aqueous ammonium sulfite were mixed and poured into the reactor, and then, the reactor was put in an oven that was already preheated to the target temperature for a certain time period according to the experimental design. After pretreatment, until the mixture was air-cooled to room temperature, the bamboo substrate

Table 2 Response surface design and composition of untreated and ammonium sulfite pretreated bamboo under different pretreatment severity levels ${ }^{a}$

\begin{tabular}{|c|c|c|c|c|c|c|c|c|c|c|c|}
\hline \multirow[b]{2}{*}{ Run } & \multicolumn{3}{|c|}{ Factors } & \multicolumn{3}{|c|}{ Composition (\%) } & \multirow{2}{*}{$\begin{array}{l}\text { Removal (\%), } \\
\text { lignin }\end{array}$} & \multirow{2}{*}{$\begin{array}{l}\text { Solid recovery } \\
\text { rate }(\%)\end{array}$} & \multirow{2}{*}{$\begin{array}{l}\text { Enzymatic hydrolysis } \\
\text { efficiency }(\%)\end{array}$} & \multicolumn{2}{|c|}{$\begin{array}{l}\text { recovery } \\
\text { yield }(\%)\end{array}$} \\
\hline & $\mathrm{C}$ & $\mathrm{T}$ & $\mathrm{H}$ & Glucan & Xylan & Lignin & & & & ${ }^{b} \operatorname{Exp}$ & ${ }^{c}$ Pred \\
\hline CK & - & - & - & $42.22 \pm 0.23$ & $17.51 \pm 0.36$ & $29.37 \pm 0.02$ & - & 100 & 4.41 & - & - \\
\hline 1 & 20 & 6 & 150 & $55.66 \pm 1.02$ & $17.76 \pm 0.12$ & $11.58 \pm 0.01$ & 37.08 & 71.30 & 83.97 & 59.87 & 58.87 \\
\hline 2 & 20 & 6 & 150 & $57.12 \pm 0.84$ & $18.21 \pm 0.48$ & $11.09 \pm 0.00$ & 37.83 & 70.54 & 82.73 & 58.36 & 58.87 \\
\hline 3 & 10 & 6 & 120 & $46.43 \pm 0.62$ & $19.02 \pm 0.29$ & $25.87 \pm 0.01$ & 10.49 & 92.56 & 38.22 & 35.38 & 36.39 \\
\hline 4 & 20 & 9 & 180 & $57.89 \pm 0.24$ & $15.05 \pm 0.35$ & $15.99 \pm 0.00$ & 39.08 & 48.28 & 71.54 & 34.54 & 35.59 \\
\hline 5 & 20 & 6 & 150 & $56.25 \pm 0.48$ & $17.64 \pm 0.27$ & $11.32 \pm 0.01$ & 37.54 & 71.24 & 81.92 & 58.36 & 58.87 \\
\hline 6 & 20 & 6 & 150 & $56.95 \pm 0.15$ & $17.41 \pm 1.12$ & $11.43 \pm 0.01$ & 37.68 & 70.71 & 82.80 & 58.55 & 58.87 \\
\hline 7 & 10 & 3 & 150 & $49.43 \pm 0.21$ & $19.21 \pm 1.14$ & $23.81 \pm 0.01$ & 17.86 & 82.33 & 34.69 & 28.56 & 28.60 \\
\hline 8 & 30 & 6 & 180 & $48.76 \pm 0.37$ & $14.97 \pm 0.89$ & $1.22 \pm 0.01$ & 64.51 & 49.72 & 63.68 & 31.66 & 30.66 \\
\hline 9 & 20 & 9 & 120 & $54.50 \pm 1.29$ & $17.34 \pm 0.57$ & $16.30 \pm 0.00$ & 13.74 & 79.34 & 53.47 & 42.42 & 42.05 \\
\hline 10 & 30 & 9 & 150 & $60.30 \pm 0.47$ & $20.63 \pm 0.31$ & $7.82 \pm 0.01$ & 55.22 & 63.28 & 57.46 & 36.36 & 36.32 \\
\hline 11 & 20 & 3 & 180 & $64.27 \pm 1.23$ & $17.36 \pm 0.34$ & $11.24 \pm 0.02$ & 46.24 & 56.21 & 50.24 & 28.24 & 28.61 \\
\hline 12 & 20 & 3 & 120 & $43.32 \pm 1.06$ & $17.78 \pm 0.41$ & $25.27 \pm 0.00$ & 15.51 & 83.69 & 61.23 & 51.24 & 50.19 \\
\hline 13 & 30 & 3 & 150 & $49.59 \pm 0.56$ & $19.33 \pm 0.51$ & $14.60 \pm 0.01$ & 30.71 & 77.24 & 56.40 & 43.56 & 44.19 \\
\hline 14 & 30 & 6 & 120 & $47.37 \pm 0.40$ & $19.05 \pm 0.21$ & $16.80 \pm 0.01$ & 18.45 & 78.61 & 60.88 & 47.86 & 48.27 \\
\hline 15 & 20 & 6 & 150 & $55.98 \pm 1.04$ & $18.35 \pm 0.16$ & $11.74 \pm 0.01$ & 37.92 & 71.04 & 83.35 & 59.21 & 58.87 \\
\hline 16 & 10 & 6 & 180 & $57.17 \pm 1.48$ & $2.06 \pm 0.20$ & $38.78 \pm 0.00$ & 25.07 & 63.06 & 83.35 & 26.37 & 25.96 \\
\hline 17 & 10 & 9 & 150 & $44.09 \pm 0.65$ & $4.52 \pm 0.51$ & $23.04 \pm 0.03$ & 28.23 & 65.88 & 54.58 & 35.96 & 35.32 \\
\hline
\end{tabular}

${ }^{a}$ CK-control check (untreated raw bamboo). $C$-concentration (\%). $T$-temperature $\left({ }^{\circ} \mathrm{C}\right) . H$-time (h). ${ }^{b}$ Exp-experimental. ${ }^{c}$ Pred-predicted. 


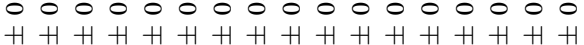

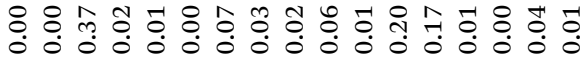

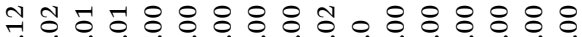

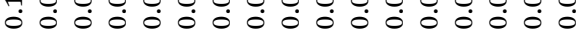
$\mathrm{H}+\mathrm{H}+\mathrm{H}+\mathrm{H}+\mathrm{H}+\mathrm{H}+\mathrm{H}+\mathrm{H}+\mathrm{H}+\mathrm{H}+\mathrm{H}$ 究

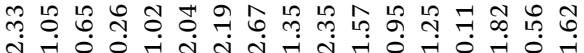
i

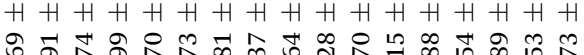

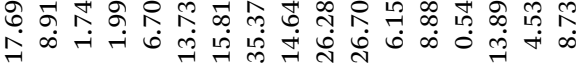
$H+H+H+H+H+H+H+H+H+H+H$ กำ ते

F

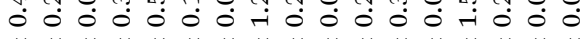
$H+H+H+H+H+H+H+H+H+H$

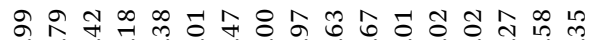
它

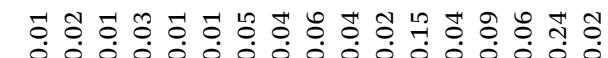
$H+H+H+H+H+H+H+H+H+H+H$

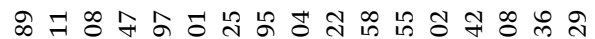

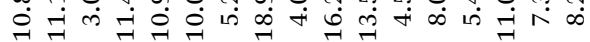

ㅇำ

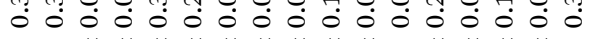

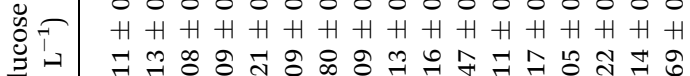

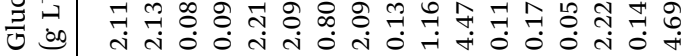
ธี ซี

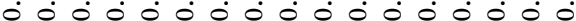

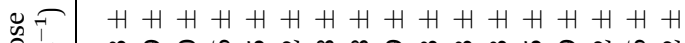
不

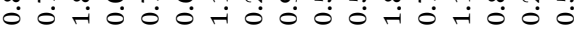

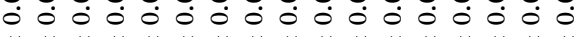
$\mathrm{H}+\mathrm{H} H \mathrm{H} H \mathrm{H} H \mathrm{H}+\mathrm{H} H \mathrm{H}+\mathrm{H}+\mathrm{H}+\mathrm{H} H$

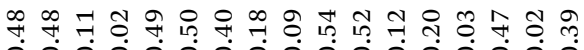

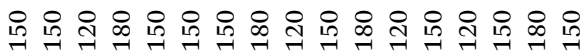
o

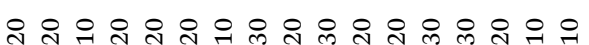

and spent liquid were separated by vacuum filtration using a water-circulation multifunction vacuum pump. The pretreated substrate was washed several times with distilled water until the washing water became colourless, then weighed, and stored in a sealed plastic bag at $4{ }^{\circ} \mathrm{C}$ for further analysis and enzymatic hydrolysis. Some of the pretreated biomass was oven dried, and the moisture content was calculated. The pretreatment experiments were conducted in duplicate. The solid recovery was determined by the following equation:

$$
\text { Solid recovery }(\%)=\frac{m_{\mathrm{ps}} \times\left(1-\mathrm{MC}_{\mathrm{ps}}\right)}{m_{\mathrm{rb}} \times\left(1-\mathrm{MC}_{\mathrm{rb}}\right)} \times 100
$$

where $m_{\mathrm{ps}}=$ the mass weight of the pretreated substrate, $\mathrm{g}$; $\mathrm{MC}_{\mathrm{ps}}=$ the moisture content of the pretreated substrate, $\%$; $m_{\mathrm{rb}}=$ the mass weight of raw bamboo, $\mathrm{g} ; \mathrm{MC}_{\mathrm{rb}}=$ the moisture content of raw bamboo, \%.

\subsection{Enzymatic hydrolysis}

Enzymatic hydrolysis was carried out in a $50 \mathrm{~mL}$ plastic centrifuge tube with a certain weighed substrate that contained equivalent to $0.44 \mathrm{~g}$ glucan, $20 \mathrm{~mL}$ acetic acid/sodium acetate buffer $(\mathrm{pH}=4.8)$, tetracycline (that was placed to prevent microbial growth) and cellulose; $\beta$-glucosidase was added at 15 FPU per $g$ glucan and 30 IU per $g$ glucan. The mixture was then put in an incubator shaker at $50{ }^{\circ} \mathrm{C}$ with $120 \mathrm{rpm}$ for $48 \mathrm{~h}$. Then, the supernatant was obtained and filtered through a membrane (pore size of $0.45 \mu \mathrm{m}$ ) for the further analysis of glucose content. The data are presented as the average of duplicates from each experimental substrate.

The enzymatic hydrolysis efficiency was calculated by the following equation:

Enzymatic hydrolysis efficiency $(\%)=($ glucose content in the liquid supernatant after enzymatic hydrolysis $\times 0.9$ /glucose content in liquid after pretreatment) $\times 100$

\subsection{Chemical composition analysis}

The chemical composition analysis of raw bamboo, pretreated and washed bamboo substrates and spent liquors was conducted by a two-step sulfuric acid hydrolysis method following the National Renewable Energy Laboratory (NREL) analytical procedure. ${ }^{19}$ The substrate was prehydrolyzed by $72 \%$ sulfuric acid for $2 \mathrm{~h}$ at room temperature, and then, the mixture was transferred to a conical flask and diluted to $3 \%$ sulfuric acid with $287.5 \mathrm{~mL}$ distilled water for further hydrolysis for $1 \mathrm{~h}$ at $121{ }^{\circ} \mathrm{C}$ in an autoclave. The pretreated spent liquor was also hydrolyzed by $3 \%$ sulfuric acid under the same condition. The liquid after hydrolysis was obtained for monosaccharide and acid-soluble lignin analysis. The lignin removal was determined by the following equation:

$$
\text { Lignin removal }(\%)=\left(1-\frac{L_{\mathrm{pl}}}{L_{\mathrm{rb}}}\right) \times 100
$$


Table 4 ANOVA for the response surface quadratic model for total cellulose recovery yield ${ }^{a}$

\begin{tabular}{|c|c|c|c|c|c|c|}
\hline Source & Sum of squares & DF & Mean square & $F$ value & $P$-value prob. $>F$ & Significance \\
\hline Model & 2398.84 & 9 & 266.45 & 252.69 & $<0.0001$ & $* *$ \\
\hline$A$ & 137.53 & 1 & 137.53 & 130.38 & $<0.0001$ & $* *$ \\
\hline$C$ & 393.26 & 1 & 393.26 & 372.82 & $<0.0001$ & $* *$ \\
\hline$A B$ & 53.29 & 1 & 53.29 & 50.52 & 0.0002 & $* *$ \\
\hline$A C$ & 12.92 & 1 & 12.92 & 12.25 & 0.0100 & $* *$ \\
\hline$B^{2}$ & 378.70 & 1 & 378.70 & 359.02 & $<0.0001$ & $* *$ \\
\hline$C^{2}$ & 444.64 & 1 & 444.64 & 421.53 & $<0.0001$ & $* *$ \\
\hline Residual & 7.38 & 7 & 1.05 & & & \\
\hline Lack of fit & 5.65 & 3 & 1.88 & 4.33 & 0.0954 & Not significant \\
\hline Pure error & 1.74 & 4 & 0.43 & & & \\
\hline Corrected total & 2406.22 & 16 & & & & \\
\hline
\end{tabular}

where $L_{\mathrm{pl}}=$ the lignin content of the pretreated bamboo substrates, $\mathrm{g} ; L_{\mathrm{rb}}=$ the lignin content of raw bamboo, $\mathrm{g}$.

The monosaccharide concentrations were analyzed by ion chromatography using an amperometric detector (Metrohm Corporation, Switzerland). Detection was performed at $32{ }^{\circ} \mathrm{C}$ using the Hamilton RCX-30 column and Metrosep RP2 guard column. The cellulose content was presented by the glucose concentration. Moreover, the hemicellulose content was the combination of the concentrations of xylose, arabinose, galactose and mannose.

The acid-soluble lignin was analyzed at $205 \mathrm{~nm}$ via a UVvisible spectrophotometer using $3 \%$ sulfuric acid as the control blank. Acid-insoluble lignin of all the samples was determined by the weight of the residues after the two-step sulfuric acid hydrolysis. Fermentation inhibitors, including acetic acid, formic acid, furfural, levulinic acid and 5-hydroxylmethylfurural (HMF), were degraded from cellulose and hemicellulose during the pretreatment process. They were analyzed using a highperformance liquid chromatograph (HPLC) equipped with the Aminex HPX-87H $(30 \mathrm{~cm} \times 7.8 \mathrm{~mm})$ column at the temperature of $25{ }^{\circ} \mathrm{C}$ and a UV detector at $210 \mathrm{~nm}$. Eluent was $0.1 \%$ phosphoric acid at the rate of $0.7 \mathrm{~mL} \mathrm{~min}^{-1}$.

\subsection{Experimental design and statistical analysis}

2.5.1 Response surface model (RSM) for pretreatment. Response surface methodology (RSM) was used to investigate the combined effects of three different pretreatment parameters, i.e. pretreatment temperature, time and ammonium sulfite concentration, on the total cellulose recovery yield. The levels of factors were chosen based on preliminary trials to ensure a proper range. A set of 17 trials that ran with five replicates at central points was designed using the Design-Expert 8.0.6 software (Stat-Ease Inc., Minneapolis, MN, USA), and each of the trial points was replicated twice. All experiments were carried out in a randomized order. The independent variables between the range of -1 and 1 for all factors and the corresponding levels of the three variables are listed in Table 1 . The data were fitted with a regression model using a quadratic polynomial equation, and the fit of the model was evaluated by comparing $R^{2}$ and $R_{\mathrm{adj}}{ }^{2}$. Validations under the optimized conditions and critical conditions were performed, and the statistical analysis of the data was performed using analysis of variance (ANOVA). ${ }^{20}$

\subsection{Scanning electron microscopy (SEM)}

The changes in the surface morphologies and characteristics of the untreated and pretreated bamboo under optimized pretreatment condition were observed using an environmental scanning electron microscope (XL30 ESEM-FEG, Philips, the Netherlands). Dried samples were coated with platinum using an ion sputter coater and placed on aluminum stubs; all the images were obtained at the magnification of 500 times.

\section{Results and discussion}

\subsection{The chemical composition of pretreated bamboo substrates and spent liquor at different severity levels}

The chemical composition of all the pretreated substrates and the response surface experimental design are listed in Table 2. The pretreatment could change the chemical composition of the raw lignocellulose material and increase the enzymatic hydrolysis efficiency. The content of cellulose could increase from $42.22 \%$ to $64.27 \%$, and $46.24 \%$ lignin was removed accordingly using a $20 \%$ ammonium sulfite for $3 \mathrm{~h}$ at $180{ }^{\circ} \mathrm{C}$ (trail 11); moreover, the enzymatic hydrolysis efficiency could reach $50.24 \%$. Unfortunately, the solid substrate recovery rate was only $56.21 \%$; this might be because most of the carbohydrates were degraded to the fermentation inhibitor, as presented in Table 3. 


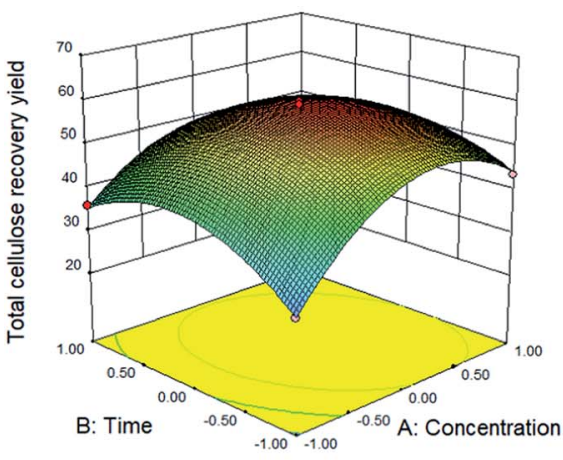

(A)

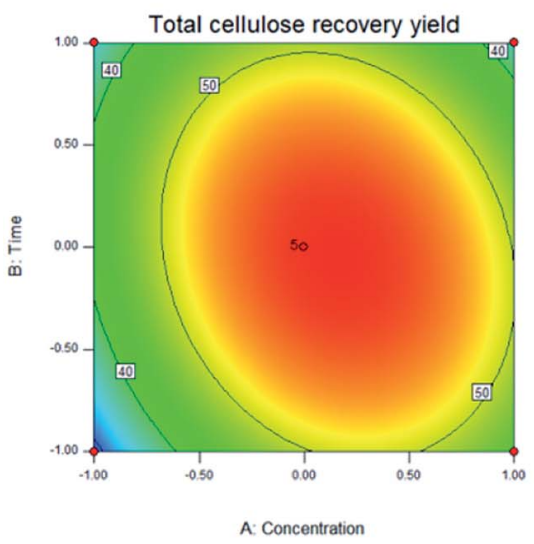

(a)

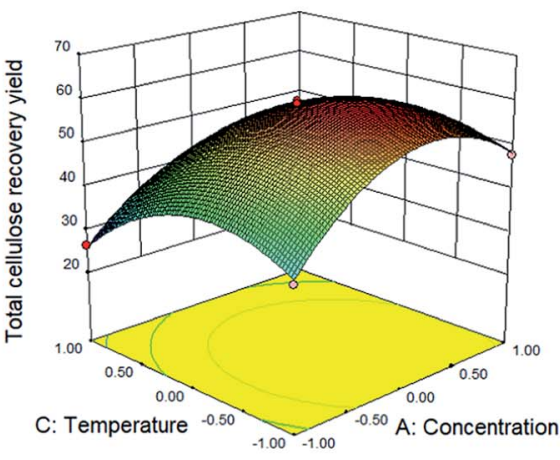

(B)

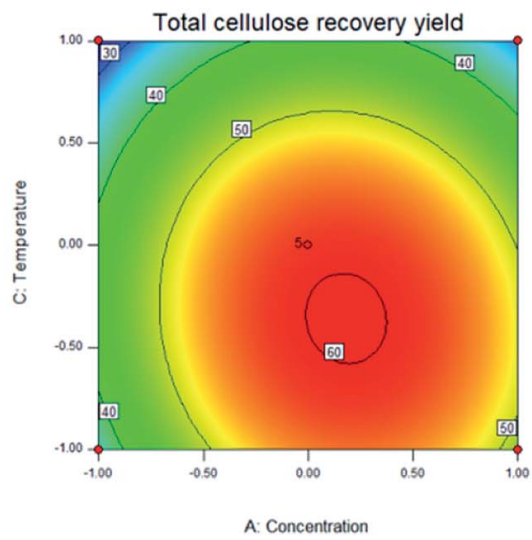

(b)

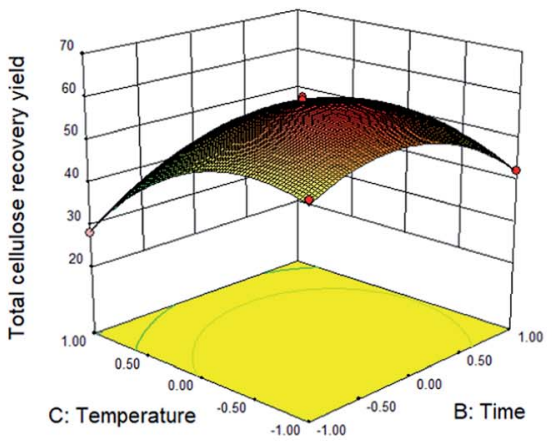

(C)

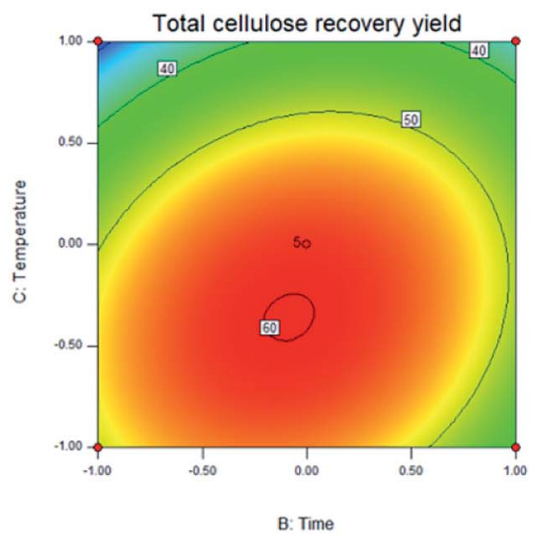

(c)

Fig. 1 3D-response surface and contour plots for the impacts of variables and their mutual effects on the cellulose recovery yield: (A and a) ammonium sulfite concentration and time; ( $B$ and $b$ ) ammonium sulfite concentration and temperature; and $(C$ and $C)$ time and temperature, respectively.

The contents of arabinose, galactose, xylose, glucose, soluble lignin and fermentation inhibitor in all the pretreated liquors are listed in Table 3. It was clearly found that the content of carbohydrate was low in the spent liquor, and the soluble lignin content was in accordance with the enzymatic hydrolysis efficiency; this meant that the content of soluble lignin in the spent liquid was increased significantly (from $3.08 \%$ to $16.22 \%$ ) after pretreatment, and the higher lignin removal could result in higher enzymatic hydrolysis efficiency.

Furfural and HMF were obtained from the dehydration of pentoses and hexoses, respectively; acetic acid was mainly obtained from the acetyl groups on hemicelluloses; moreover, levulinic and formic acids were the products of the successive decomposition of HMF. ${ }^{21}$ The contents of formic acid, acetic acid, and levulinic acid were much higher than those of furfural and HMF; this might be due to the long pretreatment time.

The chemical component in the spent liquor was extremely complicated according to the HPLC analysis. The spent liquor contained different kinds of monosaccharides, fermentation inhibitors, extractives, waxes, lignosulfonates, unreacted ammonium sulfite and so on. The cost of solvent recovery was really high. Normally, the spent liquor is used as a fertilizer. ${ }^{22}$ To fully utilize the pretreated liquor, it was subjected to pyrolysis with hydrogen to break lignin into flammable gas, whereas ammonium sulfite was decomposed into sulfur dioxide and ammonia. ${ }^{23}$

\subsection{Model fitting and statistical analysis}

The results of the experimental design are listed in Table 2. They clearly indicate that the total cellulose recovery yield for the 17 trails ranged from $26.37 \%$ to $59.87 \%$, whereas the corresponding delignification rate was in the range from $10.49 \%$ to $64.51 \%$. Significantly low reaction severity could cause higher solid recovery rate (as trial 3). Trial 1 with the solid recovery rate of $71.30 \%$ and enzymatic hydrolysis efficiency of $83.97 \%$ had the highest cellulose recovery yield of $59.87 \%$. Trial 8 had the highest lignin removal rate of $64.51 \%$ but the lower enzymatic hydrolysis efficiency of $63.68 \%$; this might be because most of the carbohydrates were degraded and transferred to the fermentation inhibitor, as presented in Table 3.

$Y_{\mathrm{TCRY}}$ was set as the responsive variable for modelling to reach the highest cellulose recovery yield, and the final quadratic polynomial model is shown by the following equation: 


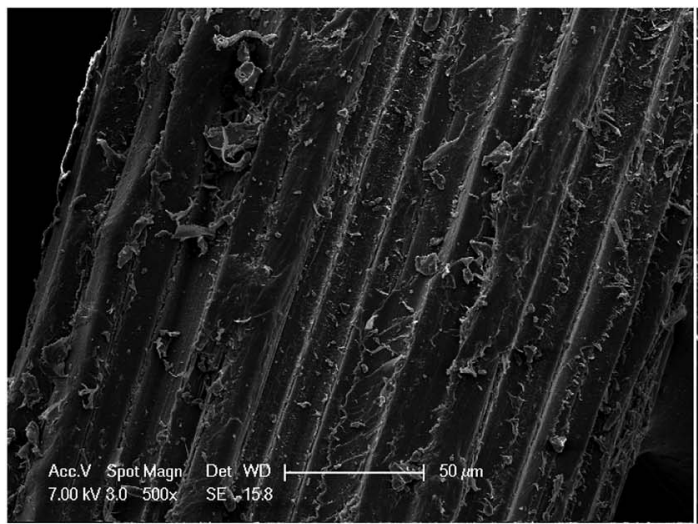

(a)

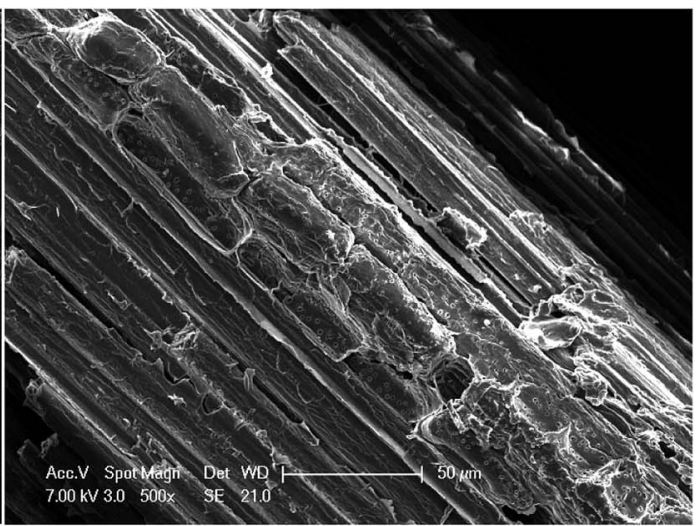

(b)

Fig. 2 The SEM images of the untreated and pretreated bamboo substrate under optimal pretreatment conditions (ammonium sulfite $20 \%$ at $150{ }^{\circ} \mathrm{C}$ for $6 \mathrm{~h}$ ): (a) untreated raw bamboo and (b) pretreated bamboo substrate.

$Y_{\mathrm{TCRY}}=+58.87+4.15 A-0.29 B-7.01 C-3.65 A B-1.80 A C+$ $3.78 B C-13.28 A^{2}-9.48 B^{2}-10.28 C^{2}$

where $A, B$ and $C$ are the concentration (\%), time (h), and temperature $\left({ }^{\circ} \mathrm{C}\right)$, respectively.

In the abovementioned equation, positive coefficients indicated a synergistic effect, whereas negative signs suggested an antagonistic effect. The analysis of variance (ANOVA) showed the possible effects of all variables on $Y_{\mathrm{TCRY}}$. The fit of the model was evaluated by comparing the $R^{2}$ and the adjusted $R_{\text {adj }}{ }^{2}$. The statistical significance was determined by an $F$-test, which should not be less than 0.80 , and the $P$-value, which should be less than 0.05 for a good fit of the developed model. ${ }^{24,25}$ The ANOVA results of the developed model are listed in Table 4 . The model fitted the data with an $R^{2}$ of 0.9969 for $Y_{\mathrm{TCRY}}$, which suggested a strong correlation coefficient between all the data. The model parameters, such as temperature and concentration, showed a high level of significance $(p<0.0001)$, whereas the time implied a low level of significance $(p=0.4507>0.05)$, and the quadratic terms $A^{2}, B^{2}$, and $C^{2}$ and the interactions of $\mathrm{AB}, \mathrm{BC}$, and $\mathrm{AC}$ were significant with the $P$-value less than 0.05 . The value of the predicted $R$-squared $\left(R_{\mathrm{pre}}^{2}=0.9613\right)$ significantly suggested the strong predictive ability of the model. The value of lack of fit $(p=0.0954>0.05)$ further indicated model adequacy. In addition, the experimental values versus the predicted values showed a high quality of fit throughout the design space (Table 2).

\subsection{Impact of variables on the response}

The 3D-response surfaces for the impacts of variables and their mutual effects on $Y_{\mathrm{TCRY}}$ are shown in Fig. $1(\mathrm{~A}-\mathrm{C})$, and the corresponding contour plots are presented in Fig. $1(\mathrm{a}-\mathrm{c})$.

The slope of the response surface could indicate the extent of the response under various pretreatment conditions, whereas the steep curved surface indicated that the response value was very sensitive to the relevant pretreatment conditions. ${ }^{20}$ Fig. $1(\mathrm{~A}-\mathrm{C})$ show the effects of two parameters on the total cellulose recovery yield. The three steep slopes clearly suggested the relatively strong interaction effect between all the pretreatment conditions. Moreover, the shape of the contour plot could reflect the intensity of the interaction effects. In general, an oval shape revealed a strong interaction of the two factors, which was opposite to the case of the circular shape ${ }^{26}$ the contour plot showed an apparent oval shape, which was in agreement with the result of the 3-D response surface.

\subsection{Model validation}

According to the model analysis, the optimized pretreatment conditions were a $20 \%$ ammonium sulfite concentration and the temperature of $150{ }^{\circ} \mathrm{C}$ with the pretreatment time of $6 \mathrm{~h}$; moreover, the best combination of pretreatment parameter level for the model predicting the total cellulose recovery yield of around $59.87 \%$ was tested experimentally for model validation, and the result was $58.56 \%$, which was in good agreement with the predicted value. In addition, the difference between the predicted and the actual values was within $3.3 \%$ (run 8 ) for all the validation treatments (Table 2).

\subsection{The surface structure of raw bamboo and the preferred substrate}

The SEM images of the untreated bamboo and the pretreated bamboo substrate under optimal pretreatment conditions are shown in Fig. 2. The surface structure of the raw bamboo demonstrated more rigid and ordered fibrils. The fiber was slightly distorted, and the surfaces appeared rough, which increased the surface area and might contribute to the accessibility of enzyme to cellulose and improve the enzymatic hydrolysis efficiency. ${ }^{27}$

\section{Conclusion}

This study was performed to quantify the effect of different pretreatment temperatures, time durations, and ammonium sulfite concentrations on the total cellulose recovery yield 
during pretreatment by the Box-Behnken design based on the response surface methodology. The total cellulose recovery yield after the $48 \mathrm{~h}$ enzymatic hydrolysis (with the cellulose loading of 15 FPU per g glucan) could reach around $59.87 \%$ with the preferred pretreatment condition of $20 \%$ ammonium sulfite at $150{ }^{\circ} \mathrm{C}$ for $6 \mathrm{~h}$.

\section{Conflicts of interest}

There are no conflicts to declare.

\section{Acknowledgements}

This research was supported by the National Key Research and Development Program of China (Project No. 2017YFD0600805).

\section{References}

1 L. Jiang, A. Zheng, Z. Zhao, F. He, H. Li and N. Wu, Bioresour. Technol., 2015, 200, 8-13.

2 K. Zhang, Z. Pei and D. Wang, Bioresour. Technol., 2016, 199, 21-33.

3 M. Rastogi and S. Shrivastava, Renewable Sustainable Energy Rev., 2017, 80, 330-340.

4 L. R. S. Moreira, N. vG. Milanezi and E. X. F. Filho, in Routes to Cellulosic Ethanol, ed. M. S. Buckeridge and G. H. Goldman, Springer, New York, 2011, ch. 6, pp. 73-96.

5 Y. Sun and J. Cheng, Bioresour. Technol., 2003, 83, 1-11.

6 N. Mosier, C. Wyman, B. Dale, R. Elander, Y. Y. Lee, M. Holtzapple and M. Ladisch, Bioresour. Technol., 2005, 96, 673-686.

7 J. R. Jensen, J. E. Morinelly, K. R. Gossen, M. J. BrodeurCampbell and D. R. Shonnard, Bioresour. Technol., 2010, 101, 2317-2325.

8 N. S. Pooja, M. S. Sajeev, M. L. Jeeva and G. Padmaja, 3 Biotech, 2018, 8, 69.

9 Z. Li, Z. Jiang and B. Fei, BioResources, 2012, 7, 3452-3462.

10 A. P. Dadi, S. Varanasi and C. A. Schall, Biotechnol. Bioeng., 2006, 95, 904-910.
11 Z. Li, B. Fei and Z. Jiang, BioResources, 2014, 10, 1037-1047.

12 J. R. G. Bryce, in Pulp and Paper: Chemistry and Chemical Technology, ed. J. P. Casey, John Wiley \& Sons, New York, 3rd edn, 1981, pp. 291-376.

13 J. Y. Zhu, X. J. Pan, G. S. Wang and R. Gleisner, Bioresour. Technol., 2009, 100, 2411-2418.

14 Z. Li, B. Fei, D. Qin and Z. Jiang, J. Biobased Mater. Bioenergy, 2017, 11, 521-526.

15 D. S. Zhang, Q. Yang, J. Y. Zhu and X. J. Pan, Bioresour. Technol., 2013, 129, 127-134.

16 O. Ingruber, in Sulfite Science and Technology, ed. O. Ingruber, M. Kocurek and A. Wong, TAPPI/CPPA, Atlanta, 3rd edn, 1985, pp. 3-23.

17 W. Hull, B. Smith, J. Hull and W. Holzer, Ind. Eng. Chem., 1954, 46, 1546-1557.

18 G. Qi, L. Xiong, L. Tian, M. Luo, X. Chen, C. Huang, H. Li and X. Chen, Sustain Energy Techn., 2018, 29, 12-18.

19 A. Sluiter, B. Hames, R. Ruiz, C. Scarlata, J. Sluiter, D. Templeton and D. Crocker, NREL/TP-510-42618, National Renewable Energy Laboratory, Golden, 2008.

20 S. Chi, G. Yu, X. Zhang, Y. Zhang, C. Liu, Z. Li, B. Li and Q. Cui, Bioresour. Technol., 2019, 14, 4603-4622.

21 Z. Li, Q. Yang, Z. Jiang, B. Fei, Z. Cai and X. Pan, J. Biobased Mater. Bioenergy, 2012, 6, 544-551.

22 S. Y. Bai and B. Y. Liu, Heilongjiang Pulp \& Paper, 2008, 36(4), 24-27.

23 A. V. Bridgwater, D. Meier and D. Radlein, Org. Geochem., 1999, 30, 1479-1493.

24 A. Ruangmee and C. Sangwichien, Energy Convers. Manage., 2013, 73, 381-388.

25 T. Auxenfans, S. Buchoux, D. Larcher, G. Husson, E. Husson and C. Sarazin, Energy Convers. Manage., 2014, 88, 10941103.

26 H. Lu, C. Lv, M. Zhang, S. Liu, J. Liu and F. Lian, Energy Convers. Manage., 2017, 132, 251-260.

27 K. E. Kang, G. T. Jeong, C. Sunwoo and D. H. Park, Bioprocess Biosyst. Eng., 2012, 35, 77-84. 